See Article page 167.

\section{Commentary: Until now, sternal elevation was sort of up in the air}

\author{
John N. Pagteilan, MD, and Anthony W. Kim, MD
}

The desired outcome of surgery for pectus excavatum is to reverse the chest wall depression, thereby alleviating the physiologic and cosmetic sequelae associated with the disease. Since its inception, the Nuss procedure has become a common and effective minimally invasive approach that has achieved this desired outcome in many circumstances. Owing to the subjective nature of the placement of the Nuss bar, over time, it has been enhanced by several modifications. One described adjunct has been to use a crane to elevate the sternum, also known as the crane technique, to facilitate the safe mediastinal passage of the Nuss bar. Despite its efficacy, there has been a paucity of objective data regarding the crane technique's intraoperative effect on the sternal defect. In fact, when using the crane technique, intraoperative correction of pectus excavatum deformity largely has been based on surgeon estimation and judgment. That is, up until now.

In their first-of-its-kind prospective study, de Loos and colleagues ${ }^{1}$ used intraoperative 3 -dimensional imaging to quantify the impact of the crane technique from 30 patients with a median Haller index of 3.56 undergoing a Nuss procedure. A median reduction of $78 \%$ in the pectus defect corresponding to a median residual depth of $3 \mathrm{~mm}$ from a median starting preoperative defect of $18 \mathrm{~mm}$ was observed. Furthermore, with the crane technique there was an overall elevation of the entire anterior thoracic wall to a median maximum lift of $26 \mathrm{~mm}$.

The authors' contribution is to be lauded; however, their study raises some questions, that if answered, could

\footnotetext{
From the Division of Thoracic Surgery, Department of Surgery, Keck School of Medicine, University of Southern California, Los Angeles, Calif.

Disclosures: The authors reported no conflicts of interest.

The Journal policy requires editors and reviewers to disclose conflicts of interest and to decline handling or reviewing manuscripts for which they may have a conflict of interest. The editors and reviewers of this article have no conflicts of interest.

Received for publication Aug 11, 2021; revisions received Aug 11, 2021; accepted for publication Aug 11, 2021; available ahead of print Aug 14, 2021.

Address for reprints: Anthony W. Kim, MD, 1510 San Pablo St, Suite 514, Los Angeles, CA 90033 (E-mail: anthony.kim@med.usc.edu).

JTCVS Techniques 2021;9:178-9

2666-2507

Copyright (c) 2021 The Authors. Published by Elsevier Inc. on behalf of The American Association for Thoracic Surgery. This is an open access article under the CC BY-NCND license (http://creativecommons.org/licenses/by-nc-nd/4.0/).

https://doi.org/10.1016/j.xjtc.2021.08.014
}

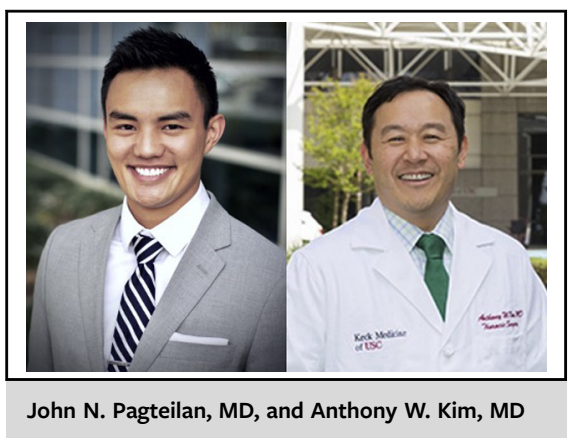

\author{
CENTRAL MESSAGE \\ Providing objective data con- \\ firming the benefits of sternal \\ elevation using the crane tech- \\ nique raises the potential to \\ further explore opportunities in \\ pectus excavatum surgery.
}

complement their early findings. Results in which a noncrane technique is employed as a control as opposed to the patients' own preoperative measurements could provide comparative data that would further support the crane technique's utility. This more robust comparative data could be used to facilitate preoperative decisionmaking to identify those patients who would benefit the most from using the crane technique. Perhaps more exciting is the possibility that with a growing experience coupling the crane technique with objective data, we may be able to witness these intraoperative measurements translating into predictive variables for durable long-term results.

While the focus of the authors' study was to quantitatively endorse the safe passage of the Nuss bar through the anterior mediastinum, 2 other interesting observations are worthy of attention. First, despite the utility of the crane technique, it alone could not completely overcome the deepest of pectus defects. Second, the crane technique yielded a general improvement of the maximum thoracic wall diameter, or essentially the entire contour, of the chest. When considering the implications of these 2 findings, one could imagine that in the era of 3-dimensional printing, this type of objective data could be used to design a Nuss bar that could realize the benefits of maximally elevating the lowest point of the defect while achieving a better chest wall contour using the crane technique. Furthermore, it reinvigorates the discussion of how the biology of pectus 
excavatum and its attendant therapy can and should be reconsidered, especially as it pertains to the deformity at its deepest point. Ultimately, adding the type of objective evidence that de Loos and associates have provided using the crane technique has the potential to augment the quality of the entire field of pectus excavatum surgery by making the act of lifting up the sternum less subjective and more scientific.

\section{Reference}

1. de Loos E, Daemen JHT, Coorens NA, Massen JG, Vissers YLJ, Hulsewe KWE Sternal elevation by the crane technique during pectus excavatum repair: a quantitative analysis. J Thorac Cardiovasc Surg Tech. 2021;9:167-75. 